\title{
Risk Factors for Recurrence of Positive SARS-CoV-2 RNA PCR in COVID-19 Convalescence: A Propensity Score Matching Study
}

\section{Wei Duan}

First Department,Huoshenshan Hospital,Wuhan;Department of Neurology,Xinqiao Hospital,Army Medical University,Chongqing

En Liu

Department of Gastroenterology,Xinqiao Hospital,Chongqing

\section{Yun Wang}

First Department ,Huoshenshan Hospital,WuHan;Department of Neurology,Xinqiao Hospital,Army Medical University,Chongqing,Chongqing

\section{Dongjing Xie}

Department of Neurology,Xinqiao Hospital,Army Medical University,Chongqing

Jialin He

First Department,Huoshenshan Hospital,Wuhan;Department of Gastroenterology,Xinqiao Hospital,Army Medical University, Chongqing

Shiming Yang ( $\nabla$ shimingyang@yahoo.com )

First Department, HuoShenShan Hospital, Wuhan, China

\section{Research}

Keywords: SARS-CoV-2, COVID-19, immune reaction, antibody, PCR test

Posted Date: October 22nd, 2020

DOl: https://doi.org/10.21203/rs.3.rs-95008/v1

License: (c) (i) This work is licensed under a Creative Commons Attribution 4.0 International License. Read Full License 


\section{Abstract}

Background Some discharged COVID-19 patients were required to be readmitted because of a positive SARS-CoV-2 PCR test at discontinuation of quarantine for 14 days. However, little is known about the clinical characteristics and underlying pathogenesis of these patients.

Methods We followed up 165 confirmed COVID-19 adult inpatients admitted to the First Department of Wuhan HuoShenShan Hospital by phone, 17 of whom were found to be positive again by throat swab SARS-CoV-2 PCR after quarantine. Thirty-four of 148 enrolled patients whose SARS-CoV-2 throat swabs were PCR negative were score matched by one-to-two propensity score matching. The clinical data were statistically analyzed between these two groups.

Results The levels of serum-specific IgM antibody in the PCR-positive group were obviously decreased compared to those in the score-matched group. Moreover, the levels of procalcitonin in the PCR-positive group were also significantly lower than those in the score-matched group.

Conclusion The increased IgM antibody against SARS-CoV-2 in humoral immunity is beneficial to the clearance of virus in COVID-19 infection. Additionally, the combination of slight bacterial infection is also conducive to the elimination of SARS-CoV-2, probably due to strengthening the immune reaction.

\section{Background}

Coronavirus disease 2019 (COVID-19), first identified as an outbreak of unknown respiratory illness in Wuhan, China, in December 2019, is a novel disease caused by severe acute respiratory syndrome coronavirus 2 (SARS-CoV-2). COVID-19 was declared a global health emergency by the WHO on March 11,2020 , and has been quickly elevated to the global pandemic $[1,2]$. Based on the clinical features of SARS-CoV-2, the Chinese Management Guideline for COVID-19 Pneumonia was rapidly issued and gradually modified for improvements. Discharge criteria in the Chinese Management Guideline for COVID-

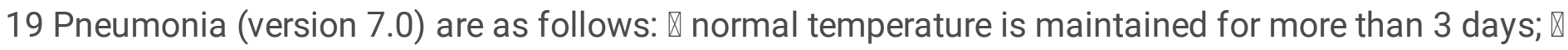
the symptoms of the respiratory tract are obviously relieved; $\triangle$ acute exudative pulmonary lesions on chest computed tomography (CT) are substantially absorbed; and $\nabla$ two consecutive SARS-CoV-2 realtime reverse transcription polymerase chain reaction (RT-PCR) tests on nasopharyngeal swab samples were negative for at least a 24-hour interval. The COVID-19 patients who meet these four criteria are allowed to be discharged from the hospital. However, since February 2020, it is disturbing that the COVID19 patients who met the criteria for hospital discharge were found to be RT-PCR positive again at discontinuation of quarantine for 14 days $[3,4]$. These important findings bring urgent attention to current criteria for hospital discharge or duration of quarantine follow-up. However, little is known about the clinical characteristics and underlying pathogenesis of these discharged patients who are PCR-positive again.

In the present study, we analyzed the clinical data of the confirmed COVID-19 hospitalized patients from the First Department in Wuhan HuoShenShan Hospital, including their SARS-CoV-2 RT-PCR test and chest 
CT. The aim of this study was to investigate the risk factors for discharged COVID-19 patients who were PCR-positive again in convalescence.

\section{Methods}

\section{Patients}

This observational study analyzed the details of clinical data for 165 confirmed COVID-19 adult hospitalized patients ( $>18$ years old) admitted to the First Department of Wuhan HuoShenShan Hospital between Feb 10, 2020 and Apr 10, 2020. Through follow-up by phone, we found 17 patients who were admitted to the hospital again because their throat swab samples were PCR positive for SARS-CoV-2 RNA after quarantine treatment for 14 days. As shown in Fig. 1, 34 of 148 enrolled patients whose SARS-CoV-2 throat swab samples were PCR negative were score matched by one-to-two propensity score matching. In the end, the clinical characteristics and examination results were statistically compared between 17 PCRpositive patients and 34 score-matched patients.

All 165 enrolled hospitalized patients were diagnosed with COVID-19 according to WHO interim guidance and Chinese Management Guideline for COVID-19 (version 7.0). The illness severity of COVID-19 hospitalized patients defined according to the Chinese Management Guideline for COVID-19 (version 7.0) was general type or severe type. However, neither noninvasive nor invasive ventilation nor intensive care was required during hospitalization. Immune-modulatory or immune-suppressive treatments were not used in the study, such as glucocorticoids, convalescent plasma therapy, antirheumatic drugs, interleukin (IL)-6 and IL-1 antagonists.

\section{Laboratory and chest CT examinations}

Routine blood examinations, performed during 6:30 a.m.-7:30 a.m. on the second morning after admission were complete blood count, coagulation profile, serum biochemical tests (including renal and liver function, creatine kinase, lactate dehydrogenase, and electrolytes), myocardial enzymes and procalcitonin. Additionally, serum-specific antibodies (IgM and IgG) against SARS-CoV-2 were also examined before discharge. Methods for laboratory confirmation of SARS-CoV-2 infection in respiratory specimens were detected by RT-PCR methods in Wuhan HuoShenShan Hospital. Two throat swab specimens were obtained for SARS-CoV-2 PCR re-examination every other day before discharge. Chest CT scans were also performed for all inpatients. The frequency of chest CT examination was determined by the treating physician.

\section{Statistical analysis}

Propensity score matching analysis was performed using logistic regression analysis to create a propensity score for the PCR-positive group and the score-matched group with a logistic regression model. Enrolled patients were statistically matched with patients admitted with COVID-19 at an approximate ratio of 2:1 based on age and sex. One-to-two score matching without replacement was 
performed within the minimum propensity score, and the resulting score-matched pairs were used in subsequent analyses.

Values for continuous variables are presented as a median and range. Nominal variables are expressed as a number (\%). Nonparametric quantitative data were analyzed using Fisher's $t$ test. The chi-square test was performed to analyze nominal variables. $P$ values $<0.05$ were considered significant. Statistical analyses were performed using SPSS software (version 22; IBM Corp., Armonk, NY, USA).

\section{Results}

As shown in Table 1, there was no significant difference in age between the PCR-positive group and the score-matched group after propensity score matching. The detailed clinical characteristics of both the PCR-positive-again and score-matched groups are presented in Table 2, in which there was no marked difference in all variables between the two groups. As shown in Table 3, the results of the laboratory test and chest CT were statistically compared using Fisher's t test. The levels of serum-specific IgM antibody against SARS-CoV-2 in the PCR-positive group were obviously decreased compared to those in the scorematched group. Moreover, the levels of procalcitonin in the PCR-positive group were significantly lower than those in the score-matched group. Nevertheless, no significant differences were found between these two groups in the other variables in Table 3.

\section{Discussion}

Recent pathological examination revealed that SARS-CoV-2 remained in pneumocytes and virus-caused lung lesions by postmortem pathologic study in a ready-for-discharge COVID-19 patient who succumbed to a sudden cardiovascular accident[5]. These results suggest that the SARS-CoV-2 in discharged patients has not been completely cleared. The effective antiviral responses of the host both in cell-mediated and humoral immunity are essential for controlling viral replication, limiting the spread of virus, inflammation and cleaning the infected cells[6-8]. It is well known that T cell immunity plays an important role in SARSCoV-2 infection. The lower the absolute value of $T$ lymphocytes before treatment, especially CD4+ T lymphocytes, the longer the duration of virus clearance $[9,10]$. Since serum-specific antibodies against SARS-CoV-2 could be detected, the more significant role that B cells play was revealed in COVID-19 infection. The serologic antibody test is helpful for the diagnosis of SARS-CoV-2 infection[11, 12] The present study shows that compared to the score-matched group, the levels of serum-specific IgM antibody against SARS-CoV-2, first produced by B cells in primary humoral immunity, were significantly lower in the PCR-positive group. There was no obvious difference in the levels of serum-specific lgG antibody between the PCR-positive group and the score-matched group. These findings suggest that serum-specific IgM antibody, the most crucial serum immunoglobulin in primary humoral immunity, plays a critical role in the clearance of virus in the early phase of COVID-19 infection. The immune role of $B$ lymphocytes in clearing virus was also demonstrated by the observation that children appeared to be more resistant to SARS-CoV-2 in the early phase of infection, possibly because their B lymphocytes are able to generate natural antibodies in a timely manner upon encountering novel pathogens when 
compared to B cells from adults[13]. Nevertheless, some published case reports showed that treatment with a B-cell depleting monoclonal antibody played a protective role in COVID-19[14]. Additionally, COVID19 patients with primary antibody deficiency had mild symptoms and fewer complications[15]. The possible cause for these results was the proinflammatory factors produced by B cells, especially IL-6, which is involved in cytokine storm syndrome (CSS). The proinflammatory role of B cells, rather than the immune function of B cells in COVID-19 infection, was emphasized.

More importantly, we found that the levels of procalcitonin in the PCR-positive-again group were markedly reduced compared to those in the score-matched group. The findings suggest that COVID-19 patients combined with slight bacterial infection probably enhance the primary humoral immune response and promote the production of serum-specific $\operatorname{lgM}$ antibody in the early stage, which plays an important role in the clearance of SARS-CoV-2. Procalcitonin is a $13 \mathrm{kDa}$ glycoprotein that is produced by parathyroid cells under normal physiological conditions. It is also called thyrocalcitonin. However, in bacterial infection, liver macrophages and monocytes, lymphocytes and endocrine cells of lung and intestinal tissues can also secrete procalcitonin under the action of endotoxin, tumor necrosis factors and interleukin-6, and the serum procalcitonin level was significantly increased. Compared with other markers of infection, procalcitonin has a better specificity for bacterial infection. The increase in procalcitonin levels occurs earlier than that of other markers of infection, which can be used for the early diagnosis of infection.

Procalcitonin is a type of acute phase reaction protein that has levels that reflect the activity of infectious diseases. Viral infection and nonspecific inflammation do not lead to elevated procalcitonin levels, but bacterial infection, severe shock, and multiple organ dysfunction syndrome (MODS) can all lead to significantly elevated procalcitonin levels. When systemic infection, severe inflammation or sepsis occurs, the level of procalcitonin in the patient's peripheral blood will increase rapidly. According to the expert consensus of emergency clinical application of procalcitonin (PCT) in China, the levels of procalcitonin in patients with systemic inflammatory response syndrome (sirs), sepsis and septic shock increased in turn and were positively correlated with the severity of the disease.

The increase in PCT concentration was not affected by the immunosuppression state of the body. In the sepsis model, the high inflammatory reaction was often accompanied by the immunosuppression stage, which was more likely to be accompanied by MODS and secondary infection. Clinical outcome is often determined by the balance of inflammatory response and immunosuppressive status. In a succinct metaanalysis of COVID-19 and PCT from Italy, the small amount of data available thus far indicates that continuous measurement of procalcitonin may play a role in predicting the progression of the disease to a more severe form, since production and release of parathyroid-derived calcitonin are greatly amplified during bacterial infection, and interleukin and elevated levels of tumor necrosis factor-a (TNF-a) and IL-6 actively maintain calcitonin. However, synthesis of the biomarker is inhibited by interferon, whose concentration increases during viral infection. Therefore, in patients with COVID-19, procalcitonin levels may return to normal. Inflammation can activate the body's immune response, and from our data, it is 
possible to confirm, precisely because of a slight increase in PCT, on the basis of ruling out coinfection with bacteria, that the autoimmune response can help the body clear the new coronavirus.

\section{Conclusion}

In brief, the higher levels of specific IgM against SARS-CoV-2 produced in humoral immunity are beneficial to virus clearance in COVID-19 infection. Additionally, the combination of mild bacterial infection is also conducive to the elimination of SARS-CoV-2, probably due to strengthening the immune reaction.

\section{Declarations}

\section{Ethical Approval and Consent to participate}

The study was approved by the ethics committee of Xinqiao Hospital (2020-yd073-01), and written informed consent was waived due to the retrospective nature of the study.

\section{Consent for publication}

Not applicable.

\section{Competing interests}

The authors declare they have no competing interests.

\section{Funding}

Not applicable.

\section{Authors' contributions}

Wei Duan and En Liu consulted on and analyzed study data, drafted, revised, and approved the final study manuscript. Yun Wang and Dongjing Xie analyzed study data, read, revised, and approved the final study manuscript. Jialin He and Shiming Yang conceived and designed the research, obtained study data, conducted preliminary data analysis, drafted, revised, and approved final study manuscript. All authors read and approved the final study manuscript.

\section{Acknowledgements}

Not applicable.

\section{Authors' information}

First Department, HuoShenShan Hospital, Wuhan, 430000खChina 
Wei Duan, Yun Wang, Jialin He, Shiming Yang

Department of Gastroenterology, Xinqiao Hospital, Army Medical University, Chongqing, 400037区China.

En Liu, Jialin He, Shiming Yang

Department of Neurology, Xinqiao Hospital, Army Medical University, Chongqing, 400037凶China.

Wei Duan, Yun Wang, Dongjing Xie

\section{References}

1. Wang D, Hu B, Hu C, Zhu F, Liu X, Zhang J, Wang B, Xiang H, Cheng Z, Xiong Y, et al: Clinical Characteristics of 138 Hospitalized Patients With 2019 Novel Coronavirus-Infected Pneumonia in Wuhan, China.JAMA 2020.

2. Sohrabi C, Alsafi Z, O'Neill N, Khan M, Kerwan A, Al-Jabir A, losifidis C, Agha R: World Health Organization declares global emergency: A review of the 2019 novel coronavirus (COVID-19).Int $J$ Surg 2020, 76:71-76.

3. Lan L, Xu D, Ye G, Xia C, Wang S, Li Y, Xu H: Positive RT-PCR Test Results in Patients Recovered From COVID-19.JAMA 2020.

4. Chen D, Xu W, Lei Z, Huang Z, Liu J, Gao Z, Peng L: Recurrence of positive SARS-CoV-2 RNA in COVID-19: A case report.Int J Infect Dis 2020, 93:297-299.

5. Yao XH, He ZC, Li TY, Zhang HR, Wang Y, Mou H, Guo Q, Yu SC, Ding Y, Liu X, et al: Pathological evidence for residual SARS-CoV-2 in pulmonary tissues of a ready-for-discharge patient.Cell Res 2020, 30:541-543.

6. Rokni M, Ghasemi V, Tavakoli Z: Immune responses and pathogenesis of SARS-CoV-2 during an outbreak in Iran: Comparison with SARS and MERS.Rev Med Virol 2020, 30:e2107.

7. Ivashkiv LB, Donlin LT: Regulation of type I interferon responses.Nat Rev Immuno/ 2014, 14:36-49.

8. Li G, Fan Y, Lai Y, Han T, Li Z, Zhou P, Pan P, Wang W, Hu D, Liu X, et al: Coronavirus infections and immune responses.J Med Virol 2020, 92:424-432.

9. Ling Y, Xu SB, Lin YX, Tian D, Zhu ZQ, Dai FH, Wu F, Song ZG, Huang W, Chen J, et al: Persistence and clearance of viral RNA in 2019 novel coronavirus disease rehabilitation patients. Chin Med J (Engl) 2020, 133:1039-1043.

10. Tufan A, Avanoglu Guler A, Matucci-Cerinic M: COVID-19, immune system response, hyperinflammation and repurposing antirheumatic drugs. Turk J Med Sci 2020, 50:620-632.

11. Zhong L, Chuan J, Gong B, Shuai P, Zhou Y, Zhang Y, Jiang Z, Zhang D, Liu X, Ma S, et al: Detection of serum IgM and IgG for COVID-19 diagnosis.Sci China Life Sci 2020, 63:777-780.

12. Lee YL, Liao CH, Liu PY, Cheng CY, Chung MY, Liu CE, Chang SY, Hsueh PR: Dynamics of anti-SARSCov-2 IgM and IgG antibodies among COVID-19 patients.J Infect 2020. 
13. Grimsholm O, Piano Mortari E, Davydov AN, Shugay M, Obraztsova AS, Bocci C, Marasco E, Marcellini V, Aranburu A, Farroni C, et al: The Interplay between CD27(dull) and CD27(bright) B Cells Ensures the Flexibility, Stability, and Resilience of Human B Cell Memory.Cell Rep 2020, 30:29632977 e2966.

14. Novi G, Mikulska M, Briano F, Toscanini F, Tazza F, Uccelli A, Inglese M: COVID-19 in a MS patient treated with ocrelizumab: does immunosuppression have a protective role? Mult Scler Relat Disord 2020, 42:102120.

15. Quinti I, Lougaris V, Milito C, Cinetto F, Pecoraro A, Mezzaroma I, Mastroianni CM, Turriziani O, Bondioni MP, Filippini M, et al: A possible role for B cells in COVID-19? Lesson from patients with agammaglobulinemia.J Allergy Clin Immunol 2020.

\section{Tables}

Table.1 One-to-two propensity score matching

\begin{tabular}{|c|c|c|c|c|c|c|}
\hline \multirow[t]{2}{*}{ Variables } & \multicolumn{3}{|c|}{ Before matching } & \multicolumn{3}{|c|}{ After matching } \\
\hline & $\begin{array}{l}\text { PCR-positive- } \\
\text { again patients } \\
(n=17)\end{array}$ & $\begin{array}{l}\text { All-involved } \\
\text { patients } \\
(n=148)\end{array}$ & $\begin{array}{l}P \\
\text { value }\end{array}$ & $\begin{array}{l}\text { PCR- } \\
\text { positive- } \\
\text { again } \\
\text { group } \\
(n=17)\end{array}$ & $\begin{array}{l}\text { Score- } \\
\text { matched } \\
\text { group } \\
(n=34)\end{array}$ & $\begin{array}{l}P \\
\text { value }\end{array}$ \\
\hline age & $52.24 \pm 15.79$ & $62.03 \pm 12.71$ & $0.004^{\star}$ & $52.24 \pm 15.79$ & $52.71 \pm 14.12$ & 0.915 \\
\hline $\begin{array}{l}\text { Sex } \\
\text { (male/female) }\end{array}$ & $12 / 5$ & $82 / 72$ & 0.173 & $12 / 5$ & $23 / 11$ & 0831 \\
\hline
\end{tabular}

One-to-two propensity score-matching was performed. The two variables, age and sex, were entered into the propensity model. Variables in bold are statistically significant $(P<0.05)$.

Table. 2 Comparison of clinical characteristics between PCR-positive-again group and score-matched group 


\begin{tabular}{|c|c|c|c|c|}
\hline Variables & $\begin{array}{l}\text { PCR-positive-again } \\
\text { group } \\
(n=17)\end{array}$ & $\begin{array}{l}\text { Score-matched } \\
\text { group } \\
(n=34)\end{array}$ & statistics & $\begin{array}{l}P \\
\text { value }\end{array}$ \\
\hline BMI & $22.43 \pm 3.10$ & $23.91 \pm 3.51$ & -1.472 & 0.147 \\
\hline \multicolumn{5}{|l|}{ Respiratory symptoms } \\
\hline $\begin{array}{l}\text { Fever } \\
\text { (temperature } \geq 37.3^{\circ} \mathrm{C} \text { ) }\end{array}$ & $15(88.24 \%)$ & $25(73.53 \%)$ & / & 0.297 \\
\hline Cough & $11(64.71 \%)$ & $20(88.24 \%)$ & 0.165 & 0.685 \\
\hline $\begin{array}{l}\text { Dyspnea } \\
\text { (>30 breaths per min) }\end{array}$ & $3(17.65 \%)$ & $11(32.35 \%)$ & / & 0.334 \\
\hline Fatigue & $4(23.53 \%)$ & $9(26.47 \%)$ & / & 1.000 \\
\hline Pectoralgia & $3(17.65 \%)$ & $2(5.88 \%)$ & / & 0.318 \\
\hline \multicolumn{5}{|l|}{ Digestive symptoms } \\
\hline Diarrhoea & $2(11.76 \%)$ & $1(2.94 \%)$ & / & 0.255 \\
\hline Abdominal pain & $0(0.00 \%)$ & $0(0.00 \%)$ & - & - \\
\hline Heart rate & $85.29 \pm 11.82$ & $84.88 \pm 14.32$ & 0.102 & 0.919 \\
\hline Systolic blood pressure & $126.71 \pm 13.10$ & $130.71 \pm 18.54$ & -0.794 & 0.431 \\
\hline Diastolic blood pressure & $79.12 \pm 11.67$ & $78.71 \pm 11.93$ & 0.117 & 0.907 \\
\hline Respiratory rate & $20.35 \pm 1.32$ & $20.91 \pm 2.97$ & -0.738 & 0.464 \\
\hline $\mathrm{SPO}_{2}$ & $97.12 \pm 2.29$ & $97.38 \pm 0.74$ & -0.465 & 0.648 \\
\hline $\begin{array}{l}\text { Time from illness onset to } \\
\text { hospital admission (days) }\end{array}$ & $27.59 \pm 15.67$ & $24.97 \pm 15.49$ & 0.567 & 0.573 \\
\hline Disease severity & & & / & 1.000 \\
\hline General type & $13(76.47 \%)$ & $25(73.53 \%)$ & & \\
\hline Severe type & $4(23.53 \%)$ & $9(26.47 \%)$ & & \\
\hline $\begin{array}{l}\text { Percent of pulmonary lesions on } \\
\text { chest CT囚\%区 }\end{array}$ & $6.51 \pm 8.71$ & $7.69 \pm 11.69$ & -0.370 & 0.713 \\
\hline $\begin{array}{l}\text { Result of PCR } \\
\text { (before admission) }\end{array}$ & & & / & 0.650 \\
\hline positive & $16(94.12 \%)$ & $29(85.29 \%)$ & & \\
\hline
\end{tabular}


Data are reported for one-to-two propensity score-matched pairs. Continuous variables are presented as a median and range. Nominal variables are expressed as a number (\%). Fisher's test or chi-square test was used to compare differences. Variables in bold are statistically significant $(P<0.05)$. BMI $=$ body mass index. $\mathrm{SPO}_{2}=$ pulse oxygen saturation

Table.3 Comparison of laboratory examinations results and chest CT between PCR-positive-again group and score-matched group 


\begin{tabular}{|c|c|c|c|c|}
\hline Variables & $\begin{array}{l}\text { PCR-positive-again } \\
\text { group } \\
(n=17)\end{array}$ & $\begin{array}{l}\text { Score-matched } \\
\text { group } \\
(n=34)\end{array}$ & statistics & $\begin{array}{l}P \\
\text { value }\end{array}$ \\
\hline WBC & $5.06 \pm 1.33$ & $5.56 \pm 1.89$ & -0.988 & 0.328 \\
\hline $\begin{array}{l}\text { Blood Neutrophil } \\
\text { absolute value }\end{array}$ & $2.98 \pm 0.98$ & $3.50 \pm 1.57$ & -1.233 & 0.224 \\
\hline Blood Neutrophil percentage & $58.59 \pm 11.02$ & $61.60 \pm 11.92$ & -0.870 & 0.389 \\
\hline $\begin{array}{l}\text { Blood Lymphocyte } \\
\text { absolute value }\end{array}$ & $1.54 \pm 0.60$ & $1.46 \pm 0.58$ & 0.437 & 0.664 \\
\hline Blood Lymphocyte percentage & $30.62 \pm 9.23$ & $29.35 \pm 13.30$ & 0.353 & 0.726 \\
\hline $\begin{array}{l}\text { Ratio of Neutrophil and } \\
\text { Lymphocyte }\end{array}$ & $2.29 \pm 1.41$ & $2.95 \pm 2.21$ & 1.258 & 0.267 \\
\hline Blood platelet & $234.88 \pm 75.96$ & $222.41 \pm 66.13$ & 0.604 & 0.549 \\
\hline $\mathrm{RBC}$ & $4.08 \pm 0.48$ & $4.18 \pm 0.66$ & -0.526 & 0.601 \\
\hline Hemoglobin & $126.59 \pm 16.41$ & $125.01 \pm 26.44$ & 0.224 & 0.824 \\
\hline ALT & $41.68 \pm 82.75$ & $26.86 \pm 21.78$ & 0.973 & 0.335 \\
\hline AST & $20.41 \pm 12.81$ & $20.69 \pm 10.03$ & -0.086 & 0.932 \\
\hline Total bilirubin & $13.27 \pm 7.25$ & $10.58 \pm 5.86$ & 1.416 & 0.163 \\
\hline Direct bilirubin & $4.56 \pm 2.54$ & $3.70 \pm 2.00$ & 1.326 & 0.191 \\
\hline Albumin & $38.62 \pm 2.89$ & $38.29 \pm 4.56$ & 0.317 & 0.753 \\
\hline $\mathrm{Na}^{+}$ & $141.88 \pm 2.53$ & $141.47 \pm 2.59$ & 0.521 & 0.605 \\
\hline $\mathrm{K}^{+}$ & $4.37 \pm 0.50$ & $4.21 \pm 0.41$ & 1.159 & 0.253 \\
\hline $\mathrm{Cl}^{-}$ & $106.10 \pm 2.16$ & $105.71 \pm 2.27$ & 0.570 & 0.571 \\
\hline Creatinine & $66.41 \pm 15.19$ & $68.05 \pm 11.81$ & -0.425 & 0.673 \\
\hline Blood urea nitrogen & $4.34 \pm 0.80$ & $4.45 \pm 1.44$ & -0358 & 0.722 \\
\hline Blood glucose & $5.66 \pm 2.16$ & $4.89 \pm 1.39$ & 1.536 & 0.131 \\
\hline CRP & $4.20 \pm 6.81$ & $12.76 \pm 24.58$ & -1.867 & 0.069 \\
\hline CK-MB & $9.54 \pm 3.47$ & $8.47 \pm 5.30$ & 0.743 & 0.461 \\
\hline Myohemoglobin & $6.65 \pm 3.71$ & $7.27 \pm 5.58$ & 0.351 & 0.727 \\
\hline
\end{tabular}




\begin{tabular}{|lllll|}
\hline Procalcitonin & $\mathbf{0 . 0 3} \pm \mathbf{0 . 0 1}$ & $\mathbf{0 . 0 6} \pm \mathbf{0 . 0 4}$ & $\mathbf{- 2 . 7 9 8}$ & $\mathbf{0 . 0 0 \mathbf { 8 } ^ { * }}$ \\
\hline PT & $12.86 \pm 1.05$ & $13.44 \pm 2.50$ & -0.744 & 0.462 \\
\hline APTT & $28.96 \pm 3.82$ & $28.56 \pm 4.10$ & 0.274 & 0.786 \\
\hline INR & $1.07 \pm 0.09$ & $1.12 \pm 0.21$ & -0.692 & 0.494 \\
\hline TT & $14.75 \pm 1.00$ & $15.21 \pm 1.39$ & -0.993 & 0.328 \\
\hline Fibrinogen & $2.81 \pm 0.46$ & $3.04 \pm 0.71$ & -0.983 & 0.332 \\
\hline D-Dimer & $0.90 \pm 0.98$ & $0.76 \pm 1.16$ & 0.347 & 0.731 \\
\hline IgG & $147.77 \pm 46.44$ & $162.66 \pm 115.78$ & -0.407 & 0.687 \\
\hline IgM & $\mathbf{3 0 . 3 2 \pm 2 0 . 9 4}$ & $\mathbf{6 6 . 0 8} \pm 57.58$ & $-\mathbf{2 . 5 4 2}$ & $\mathbf{0 . 0 1 7}$ \\
\hline IgM/IgG & $0.24 \pm 0.21$ & $0.46 \pm 0.36$ & $-\mathbf{- 1 . 4 7 9}$ & 0.145 \\
\hline
\end{tabular}

Data are reported for one-to-two propensity score-matched pairs. Continuous variables are presented as a median and range. Fisher's test was used to compare differences. Variables in bold are statistically significant $(P<0.05)$. AST = aspartate aminotransferase. $A L T=$ alanine aminotransferase. $W B C=$ white blood cell. $\mathrm{RBC}=$ red blood cell. $\mathrm{CRP}=\mathrm{C}$ reactive protein. $\quad \mathrm{CK}-\mathrm{MB}=$ creatine phosphokinase-MB. $\mathrm{PT}=$ prothrombin time. APTT = activated partial thromboplastin time. INR = international normalized ratio. TT $=$ thrombin time.

\section{Figures}




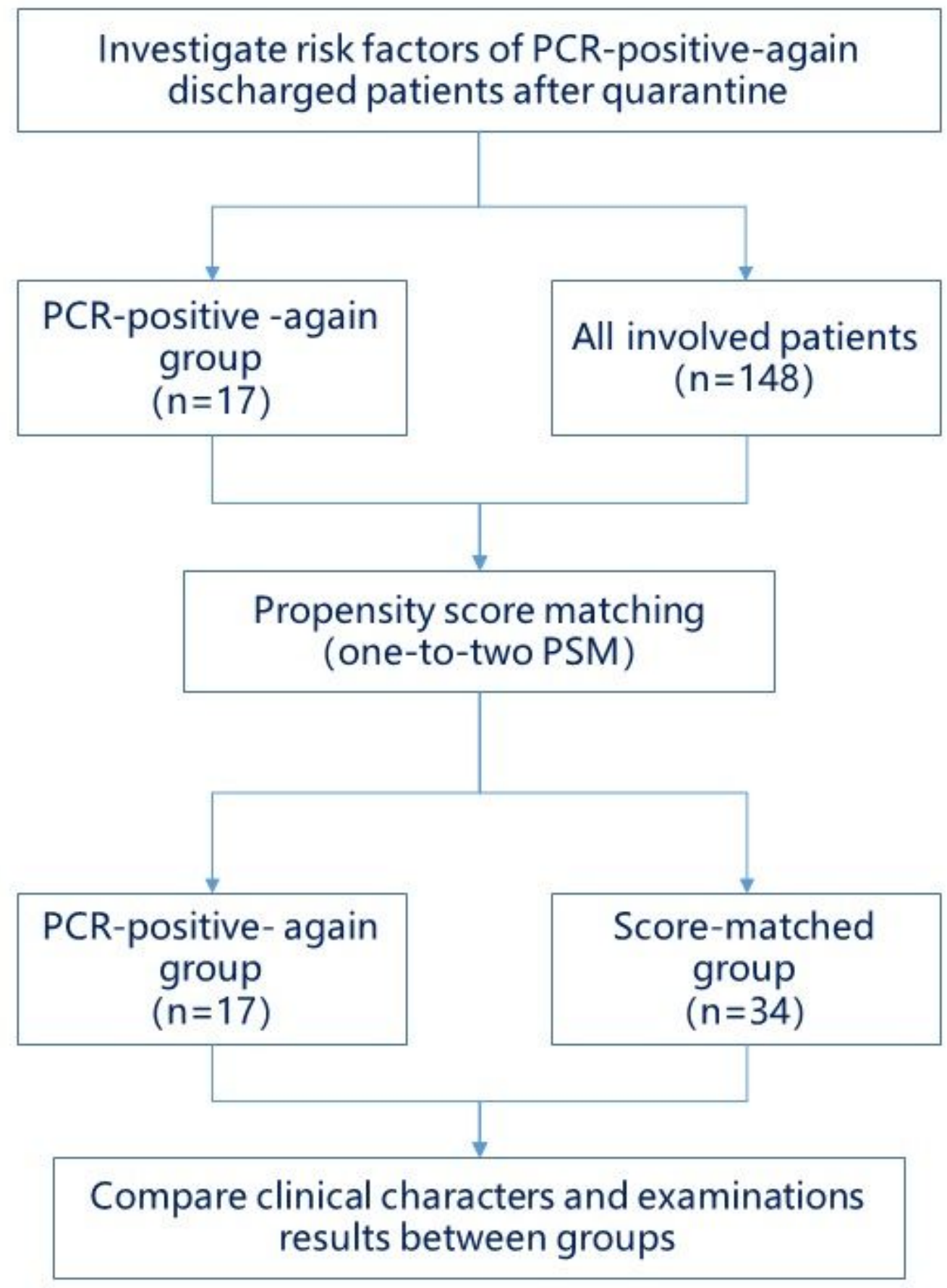

Figure 1

As shown in Fig. 1, 34 of 148 enrolled patients whose SARS-CoV-2 throat swab samples were PCR negative were score matched by one-to-two propensity score matching. In the end, the clinical characteristics and examination results were statistically compared between 17 PCR-positive patients and 34 score-matched patients. 